\title{
A estrutura do livro como matriz de ordenação do conhecimento
}

\author{
Igor Soares Amorim \\ Doutorando; Universidade Federal de Santa Catarina, Florianópolis, SC, Brasil; \\ amorim.igors@gmail.com \\ Elaine Rosangela de Oliveira Lucas \\ Doutora; Universidade do Estado de Santa Catarina, Florianópolis, SC, Brasil; \\ lani@udesc.br

\section{Daniella Camara Pizarro} \\ Doutora; Universidade do Estado de Santa Catarina, Florianópolis, SC, Brasil; \\ daniellapizarro@hotmail.com

\section{Antônio Carlos Picalho} \\ Graduando; Universidade do Estado de Santa Catarina, Florianópolis, SC, Brasil; \\ tonipicalho@gmail.com
}

\begin{abstract}
Resumo: Discute a noção de livro e como tal artefato implicou na construção da Modernidade, no sentido da compreensão do conhecimento e na circulação de informações. Caracteriza-se como uma pesquisa bibliográfica e exploratória, voltada à temática da história do livro, no período que abrange o fim da Idade Média até os dias atuais. Estabelece relações dos elementos identificados com eventos marcantes que animaram a consolidação da Modernidade para identificar efeitos que a estrutura livresca coproduziu na trajetória sociohistórica desse período. Como fundamentação teórica, parte da concepção de que o livro não é apenas um objeto, mas um elemento que se articula com o mundo. Nesse sentido, o livro não é mero suporte informacional, mero composto de conteúdo e forma. A cadeia simplificadora dado-informaçãoconhecimento é questionada, por ser uma divisão instrumental, condicionada por uma visão mecanicista da razão. Desse modo, a noção de livro deste estudo defende que antes de ter um sujeito (autor) e um objeto (assunto), tem matérias informes, de diferentes velocidades, e é definido primeiramente por sua materialidade e sua exterioridade. Essa compreensão desloca qualquer gesto documentalista ou informacional, porque categorias como autor, assunto e formato perdem relevância em relação às correlações que um livro compõe. Por isso, a necessidade de pensarmos tais correlações, de modo a rever as abordagens tradicionais que predominam nas áreas que comungam o interesse pelo livro. É necessário pensar ligações do livro com o mundo.
\end{abstract}

Palavras-chave: História do livro. Livro não-objeto. Bibliografia. Organização do conhecimento. 


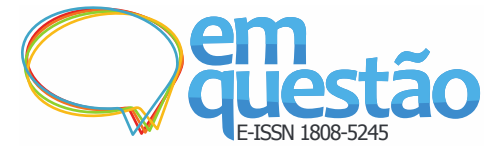

\section{Introdução}

O que é um livro? Essa pergunta permeia a discussão realizada neste artigo. O livro é um objeto de destaque no âmbito cultural, pois com ele a informação pode ser armazenada, transportada e disseminada. O aparecimento do livro possibilitou a profusão de ideias que transformaram a sociedade.

A prensa de Gutemberg, criada por volta de 1450, foi o marco na ampliação do número de publicações e na quebra do controle que instituições clericais detinham na produção dos livros. O aumento decorrente da produção condicionou a alfabetização das pessoas e um novo circuito de leitura fora dos mosteiros.

O crescimento de publicações aumentou o número das coleções e bibliotecas, as quais corroboraram as variações de sentidos sobre os livros. De artigo de poder ao direito público, o livro tornou-se objeto de fetiche, que demonstra determinadas posições de classe, vinculado ao prestígio intelectual e ao direito comum aos cidadãos da república.

No âmbito do trabalho, consolidaram-se profissões, tais como tipógrafo, editor, impressor, escritor, livreiro, bibliógrafo, entre outras. A profissão de bibliotecário é endossada na Era Moderna, preocupada em garantir a conservação e acesso aos livros. Atualmente a diversificação dos suportes faz parte do escopo da Biblioteconomia e Ciência da Informação, no entanto, o livro ainda preserva certa centralidade no discurso do campo.

É possível adotar a noção de 'livro' mais ampla do que a de um suporte no formato códice. Nesse sentido, McKenzie (2018) aproxima a noção de livro com a de texto. Porém, o mesmo autor ratifica que o suporte é condicionante simbólico do livro, do mesmo modo que seu formato é um condicionante da escrita.

Dessa forma, Haeslst (1989, p. 13 apud MELOT, 2012, p. 56) apresenta a definição de livro como "reunião de folhas de papiro ou de pergaminho dobradas em dois, agrupadas em cadernos costurados e reunidos pelo avesso e habilmente protegidas por uma capa".

No âmbito da Biblioteconomia, Bibliografia e áreas afins, dadas as preocupações com a descrição, organização e recuperação dos livros, a noção de 
livro tornou-se restrita. Ao listar as 91 regras de catalogação dos livros da biblioteca do British Museum, Panizzi (1841), ao se referir ao termo book, o associa aos dados bibliográficos. O sentido de 'livro' na lista de Panizzi, é de um apanhado de metadados relacionados à autoria, ao título, à edição, à impressão, entre outros.

Por outro lado, no âmbito da Biblioteconomia, a adoção do termo documento proposto por Otlet (2018) amplia a noção de livro e intensifica a perspectiva de um suporte que contém informações e de onde se pode extrair metadados.

O objetivo dessa pesquisa é discutir como a noção de "livro" se organizava durante a Modernidade, e como ela participava da própria organização da Modernidade. Para tanto, foi considerado como fonte de pesquisa manuais clássicos sobre o tratamento técnico de livros, e a bibliografia que trata da história do livro.

Nesse sentido, a percepção sobre o "livro" foi estudada por meio de uma abordagem bibliográfica e exploratória para revelar se o tratamento que a Biblioteconomia e áreas afins implicam uma redução no potencial expressivo do conceito de livro. Assim, uma discussão teórica foi empreendida com base na análise de bibliografias técnicas e históricas que discorrem sobre a ideia de "livro" nos séculos XVII, XVIII e XIX. Estabelecemos esses três séculos por serem um período crucial na emergência do suporte "livro" como principal meio para divulgação de ideias científicas, filosóficas e artísticas. Nesse período, consolida-se a Modernidade, suas instituições e ideais que, por sua vez, agenciam a noção "livro". Com isso, esperamos ampliar as discussões sobre o tratamento técnico da informação que a área tradicionalmente aplica.

Partimos da ideia de que o livro não é mero suporte informacional, composto de conteúdo e forma, mas um objeto que articulado com outros elementos, numa teia de relações da qual se desdobra a noção própria de livro na Modernidade. O enfoque da pesquisa centra-se nos séculos XVII, XVIII e XIX. Assim, buscamos consolidar uma análise crítica sobre a noção de 'livro' presente em obras tomadas como referenciais ao período. 
Esta pesquisa apresenta um estudo com duplo propósito: demonstrar o uso pela análise de citações extraídas de um conjunto de livros e demonstrar o potencial da utilização desse objeto durante diferentes momentos históricos. Assim, a pesquisa é justificada por sua contribuição à compreensão histórica e conceitual do livro, a partir de um viés materialista, sobretudo no contexto da Biblioteconomia e áreas afins.

Este estudo estrutura-se de modo a integrar os dados de análise a uma discussão teórica sobre a noção de livro. Na segunda seção, abordamos o livro como formato, explorando as condicionantes e implicações de sentido que o códice trouxe para a própria noção criada. Na terceira seção, abordamos o olhar bibliográfico sobre o livro a partir da análise de algumas obras que são referências aos séculos XVII, XVIII e XIX. Na quarta seção, analisamos os dados relativos à literatura recuperada no levantamento bibliográfico proposto, com base em categorias formuladas a posteriori, a fim de identificar conteúdos e viabilizar inferências. Por fim, na seção cinco, discorremos sobre a tecnização da noção de livro no campo da Biblioteconomia e Ciência da Informação, com implicações terminológicas, isto é, com a adoção do termo informação.

\section{O livro}

O livro foi, desde sua invenção até a revolução da informática, o principal suporte de armazenamento e transmissão de informações. Segundo Rasteli (2015, p. 102), o livro não tem sua significação delimitada no processo de apropriação do conhecimento e das práticas de leitura, "sua multiplicação alterou substancialmente exercícios no convívio e no relacionamento sensorial com a palavra escrita”. Para tratar do livro, é preciso fazer referência ao material e às relações que o envolvem.

O livro tal como o conhecemos, "com suas páginas imbricadas e encadernadas" (MELOT, 2012, p. 25), existe há pelo menos dois mil anos. Melot (2012) explica que a forma do livro foi o motivo pelo qual o códice obteve maior sucesso sobre outros formatos concorrentes, como rolos e placas. 
Inicialmente o códice era um pergaminho dobrado e encadernado. $\mathrm{O}$ formato foi preservado até o século $\mathrm{XV}$, quando o papel torna-se a base mais comum na produção de livros.

Melot (2012) lista algumas das principais vantagens do formato códice em relação ao rolo de pergaminho: compacto; não é quebrável; fácil manipulação; seu uso pode liberar a segunda mão para a escrita; pode ser colocado próximo ao corpo do leitor, viabilizando uso em distintas posições; condiciona uma relação de intimidade do leitor com sua forma e conteúdo; pode ser empilhado e enfileirado de modo que facilita a organização de seu conjunto; viabiliza espaços como capa e dorso para etiquetagem de identificação; facilita a indexação de suas partes na medida em que seu conteúdo é dividido por páginas; e permite ao leitor um acesso facilitado a qualquer parte do texto.

Contudo, o códice levou quase quatro séculos para tornar-se o suporte de informação de maior utilização.

O formato códice do livro foi inventado em Roma. Seus exemplares mais antigos encontrados são, em sua maioria, objetos com conteúdo cristão. Melot (2012, p. 28) afirma que o livro foi a "primeira ferramenta da mundialização", o que foi útil aos objetivos das instituições cristãs. Se a Torá era comum em rolo, o livro foi ressignificado pelo Evangelho, que implicou na renovação da mensagem. Assim, o códice e o cristianismo incentivaram a leitura silenciosa e o uso íntimo do livro. (MELOT, 2012).

$\mathrm{O}$ códice permitiu um uso trivial. Uma ferramenta cômoda para leitura e para escrita. Por isso, fora utilizado para fazer circular as cartas de São Paulo. Sua capacidade de distribuir melhor o texto pela superfície do papel foi outro fator importante. Além disso, a composição livresca permite a hierarquização de conteúdo, transpondo também a hierarquia clerical que se formava em Roma.

A inovação do códice não foi um simples ponto de reagrupamento, [...] em favor da institucionalização do cristianismo pelo Império Romano. O códice era o objeto mais apto a representar, em seu formato e em seus usos, a um só tempo, uma forma de pensamento e um modelo de sociedade. (MELOT, 2012, p. 32).

Ainda de acordo com Melot (2012), não é próprio de o livro ser suporte de um texto, muitos outros objetos podem cumprir bem essa função. O que 
melhor o livro faz é aprisionar o texto. A palavra 'aprisionamento' carrega o sentido de 'limitar' um dado conteúdo, de modo a garantir que ele torne-se inviolável: "o livro aceita projetos vastos, os quais uma vez encerrados e encadernados, conservam-se intactos dentro de uma ordem imutável.” (MELOT, 2012, p. 34). O formato do códice transmite uma sensação de segurança e autenticidade.

O lastro da dessacralização do suporte pelo cristianismo condicionou a relação do estudioso com o suporte. As condições do códice podem variar e o escriba pode rasurar, modificar e corrigir a reprodução das palavras. A dessacralização do suporte permitiu, ainda, que o poder laico adotasse o livro como ferramenta de autoridade. "O cristianismo, ao dessacralizar a materialidade do livro, abriu a via de sua laicização e de sua instrumentalização humana, colocando a forma e, por meio dela, o poder do livro sagrado no domínio público.” (MELOT, 2012, p. 34).

Se não uma sacralidade divina, uma 'sacralidade laica', uma autoridade derivada do formato e da simbologia do livro, ligada à intelectualidade, ao conhecimento fechado em uma sociedade amplamente analfabeta. Uma autoridade que se define na coletividade que perpassa pelo autor, editor, impressor, livreiro, bibliotecário, entre outros, para terminar no leitor.

O formato do livro dissimula a diversidade nas entrecapas, em um corpo visualmente unitário, conferindo-lhe certa autossuficiência. O artifício de sua unidade foi utilizado para manter a autoridade do livro por aqueles que detinham o poder ao longo da história, e ainda hoje é comum a utilização de livros para decoração de ambientes das elites. A força dessa concepção é tão grande que só recentemente passou-se a estudar a interdisciplinaridade e as questões do campo discursivo dos que tecem a noção de livro. "A forma do livro constitui um sistema" e "o livro cobre o texto, é uma pequena fortaleza", são duas noções distintas que Melot (2012, p. 49) utiliza para simbolizar a autoridade da forma. Para o autor, sua forma é uma retórica material que não tem um criador e por isso torna-se incontestável.

Melot (2012, p. 60) afirma que a "forma do livro pensa antes de ser escrita". Há uma força da própria forma, que não apenas constringe o conteúdo, 
mas compõe com ele. O livro como parte do mundo, se organiza de modo racional, em volumes, parágrafos, capítulos, pontuações, alíneas etc. A forma e a organização do livro implicam e são implicadas na e pela organização da sociedade, conforme a concepção de livro em Deleuze e Guattari (2011).

Algumas obras são exemplares nesse sentido, como a Ética de Espinoza, arranjada sob a inspiração da geometria euclidiana, uma apresentação matemática, sob o método axiomático-dedutivo. Sua organização é expressão do racionalismo que se tornava paradigma do pensamento científico e filosófico. Outra obra, Um lance de dados ${ }^{1}$, de Mallarmé, com um arranjo tipográfico revolucionário, denominado pelo próprio poeta como "subdivisões prismáticas da ideia”, levando a tipografia ao patamar das vanguardas da arte.

A leitura silenciosa foi fundamental para o estabelecimento dos valores burgueses. Ela funda um novo modelo de comunicação, abstrato, baseado na visão, no isolamento do leitor e na individualização da leitura. A emancipação burguesa teve um vetor inicial na leitura silenciosa e na biblioteca, que, ao permitir liberdade de acesso, corroborou a formação do indivíduo como cidadão.

A leitura silenciosa intensificou o exercício reflexivo e referencial, o que impulsionou as notas marginais e o paratexto, como as referências marginais, os índices e catálogos, que pululavam nas bibliotecas medievais dos séculos XI, XII e XIII. Mais uma consequência foi a utilização de outros livros para leitura de uma determinada obra.

Nesse processo dos livros auxiliares, há a compreensão da Bíblia e demandados pelas universidades, além dos livros de lazer e técnicos, que começam a se proliferar (RASTELI, 2015). A ordem alfabética surge na mesma época, mas obteve resistência, mesmo nos catálogos, pois contraria a sistematização organizada em função da voz ou da ordem clerical. A glosa nas páginas tornou-se comum e só seria padronizada com a impressão em série. (MELOT, 2012).

A indústria do livro ergueu-se junto à do papel. Febvre e Martin (2017) destacam que após a invenção de Gutemberg, fábricas de papel se espalharam rapidamente pela Europa. O papel é de fácil padronização, o que foi importante na composição do livro moderno. Assim, "o livro é antes de tudo uma norma" 
(MELOT, 2012, p. 86), pois a partir dele foi necessário normalizar o papel, a escrita, a imagem e, de certo modo, o pensamento.

A prensa móvel de Gutenberg aumentou radicalmente a produção de livros e foi elemento crucial para as mudanças na sociedade. A impressão de bíblias foi fundamental para a Reforma Protestante, a produção de literaturas alimentava o sentimento de nacionalismo diante da consolidação do Estadonação, assim como o fortalecimento de literaturas nacionais. Livros também sustentaram os avanços científicos que culminaram na Revolução Científica. (RASTELI, 2015).

A escrita mecânica, concebida por Gutenberg, foi reflexo da invenção do códice. Para Melot (2012), o livro foi a concepção da ferramenta que o comércio aguardava, dado que após a prensa de tipo móvel, curto foi o período de transformação do culto ao livro para intensificação de um mercado específico. Mesmo assim os livros mantiveram-se inacessíveis para grande parte das pessoas até o século XIX, quando se aprofundou a automatização dos processos de publicação. Prensas metálicas, prensas a rolo, a pedal, a vapor; elas tornaram a produção editorial mais eficiente e baratearam a produção. Difundiram-se, assim, livros de bolso, enciclopédias e edições de luxo. (RASTELI, 2015).

A indústria do livro pôde, ao longo da Modernidade, diversificar clientes e mercados. A diversidade de gostos e opiniões potencializou o desenvolvimento da produção dos livros. Nesse sentido, o espírito de tolerância, que se tornou a base da política moderna.

No século XVII a biblioteca torna-se responsabilidade do Estado e, com isso, o processo de formação da coleção tornou-se mais racional. Sua composição, ordenação, acesso e restrição passaram a ser feitas sob forma metódica. Para Melot (2012), foi a partir da profusão do livro que esse objeto passou a entendido como instrumento das Luzes, como uma ferramenta poderosa e perigosa ao espírito. Por isso, a biblioteca passou a ter um papel fundamental na concepção do livro na sociedade. Nesse sentido, Melot (2012, p. 108) afirma que "a biblioteca se apresenta a um só tempo como uma continuação do livro e sua metamorfose". 
Uma das produções da indústria do livro foi o desenvolvimento da folha de rosto. Em primeiro lugar sua intenção foi proteger o livro e carregar marcações, etiquetas, como um espaço reservado a receber marcas destinadas à comunicação do produto comercial que se tornou o livro. Porém, outra função foi se estabilizando e a folha de rosto passou a explicitar o título e o autor da obra. Embora fosse comum nos livros da época medieval, somente no século XVI a folha de rosto se desvencilha do resto do conteúdo do texto para tornar-se uma página específica para representação de dados sobre o livro. (MELOT, 2012).

\section{0 olhar bibliográfico sobre o livro}

O que é um livro? A pergunta continua, mas nesta seção vamos em busca do entendimento que as áreas correlatas que atuam nos processos de organização, representação e disponibilização estabeleceram a esse objeto.

O recorte desta pesquisa centra-se sobre três séculos: XVII, XVIII e XIX. Por isso, nesta seção buscamos delimitar a visão apresentada por obras de destaque que são icônicas no período de interesse: o Advis Pour Dresser une Bibliotheque (1627), de Gabriel Naudé; o código de classificação francês, de Jean-Baptiste Massieu, publicado na obra Instruction pour procéder à la confection du catalogue de chacune des bibliothèques sur lesquelles les directoires ont dû ou doivent incessamment apposer les scellés, em 1791; e, por fim, as 91 regras para compilação de catálogo de Antonio Panizzi, publicada sob o título Catalogue of Printed Books in the British Museum, em 1841.

O tratado Advis Pour Dresser une Bibliotheque, escrito por Naudé, é um dos marcos inaugurais da Biblioteconomia moderna. Na obra, várias vezes o termo livro é utilizado e expresso como objeto do bibliotecário, sendo necessário saber selecioná-lo, organizá-lo e apresentá-lo de “forma útil”.

Ao longo de sua obra, Naudé (2016) apresenta a ideia de livro sob uma perspectiva humanista. Assim, destaca o conhecimento humano dos livros e seu poder emancipador, a necessidade de garantir o acesso público e do posicionamento da biblioteca que favoreça a utilização de sua coleção. Valoriza os conhecimentos clássicos, fazendo referência aos conhecimentos de autores 
desse período, como Aristóteles, Sêneca e Cícero, mas também humanistas de destaque, como Jean Bodin, Justus Lipsius e Petrus Ramus.

Naudé conferiu à biblioteca um olhar humanista, guiado pela razão, a fim de elevar o debate sobre a arte da biblioteca, do âmbito privado e individual a uma esfera ampla, o que era demandado no alvorecer da Modernidade.

Além dos saberes contidos nos livros, o bibliotecário libertino alude também a um saber sobre os livros, o qual é referido como métier do bibliotecário. Expressa isso quando, por exemplo, apresenta sua obra: "reunir aqui as opiniões que são comuns a tantas pessoas sábias e versadas no conhecimento dos livros e dos diversos métodos adotados pelos mais famosos bibliotecários" (NAUDÉ, 2016, p. 9). Esse conhecimento sobre o livro é fundamental para avaliar livros e formar coleções. O objetivo do Advis é justamente fomentar esse saber, e é esse saber que possibilita o sucesso da biblioteca. Destacamos que, para o autor, parte desse conhecimento "não pode ser facilmente limitado a uma arte ou a um método" (NAUDÉ, 2016, p. 49), e sua fonte é a prática.

O autor separa dois universos de conhecimento sobre o livro, um técnico e outro do leitor comum, seja este um estudioso ou alguém que lê por prazer. Nesse sentido, fala em afeto com o livro, que pode levar uma pessoa ao desejo de formar uma biblioteca. O bibliotecário seiscentista afirma que há um "bem superior", uma espécie de "felicidade perfeita" derivada da posse de uma biblioteca que um homem nobre e sábio pode ter. As referências a determinada classe de homem não ocorrem sem interesse, pois, em dado momento, Naudé buscava um mecenas que pudesse alocá-lo em uma biblioteca e pagar por seus serviços.

Refere-se ao livro como "instrumento de estudo" e que existem "bons livros", o que nos permite inferir também que há "maus livros". Ao bibliotecário caberia saber identificar os "bons livros" para compor a coleção. Assim, Naudé afirma que os livros não devem ser julgados pelo seu valor monetário, pelo seu tamanho, pela encadernação, pela idade, mas pelo seu conteúdo e por sua autoria. Deve-se valorizar autores clássicos e as fontes inaugurais dos assuntos em detrimento de obras mais atuais. A autoria de algumas obras é definidora no 
processo de seleção. Naudé cita nomes cujas obras deveriam ser incorporadas à coleção “de olhos fechados, sem hesitar.” (NAUDÉ, 2016, p. 36).

Para o autor, tais critérios podem ser utilizados sempre que necessário, contudo, a biblioteca deve ter um caráter universal e, portanto, colecionar "todas as espécies de livros" (NAUDÉ, 2016, p. 23). Assim, estabelece a máxima de que "não existe livro algum, por pior e mais desprezado que seja, que, com o passar do tempo, não venha a ser procurado por alguém." (NAUDÉ, 2016, p. 24).

Sobre o livro, Naudé destaca a necessidade de preservar os aspectos físicos. Assim, o bibliotecário deve proteger os livros da umidade, da poeira, preocupar-se com o lugar de guarda e leitura e com os agentes biológicos. Destaca também que os livros são objetos a serem utilizados pelo público em geral, pois "seria vão todo esforço de alguém [...] se esse alguém não pretendesse destiná-los e consagrá-los ao uso do público, e jamais negá-los ao mais humilde dos homens que deles vier a precisar." (NAUDÉ, 2016, p. 79).

No que concerne à Organização do Conhecimento, destaca que a ordem entre os livros é tão necessária que uma coleção desordenada não é qualificada como uma biblioteca. Crítico à disposição dos livros sobre mesas, como era comum na Idade Média, Naudé defende a distribuição de livros em prateleiras: "os livros não são mais colocados sobre mesas, à moda antiga, mas em estantes que recobrem todas as paredes.” (NAUDÉ, 2016, p. 77).

Para o autor, o catálogo, além de auxiliar na gestão do acervo, tem o poder de conferir fama ao proprietário da biblioteca e ao bibliotecário, por expor as qualidades da biblioteca.

A obra de Naudé transmite a ideia de um livro portador de um conhecimento que deve ser público. O livro como um bem que deve ser cuidado a tal ponto que o Advis é apresentado como obra para abertura de um debate entre interessados no assunto. Destaca que formar uma biblioteca é tarefa para os homens sábios, e defende que o bibliotecário é o profissional adequado para tratar dos livros, com saberes sobre eles saberes adquiridos pela leitura, mas também pela prática. Ressalta a simbologia que uma biblioteca agrega ao seu proprietário, que também pode ser expressa pelo catálogo. Não detalha o 
processo de classificação ou descrição, embora estabeleça classes nas quais os livros devam ser distribuídos, assim como a necessidade de cuidar de sua dimensão física.

Neste trabalho, adotamos a noção de livro implicada no Advis como representativa para o século XVII, uma concepção humanista, que valoriza o livro a partir do que esse objeto propicia ao homem, rechaçando o sobrenatural em prol de um conhecimento que dignifica os homens e suas capacidades racionais. Valoriza os saberes clássicos em detrimento da escolástica e ratifica o livro como símbolo de prestígio numa sociedade em que o governo se distancia do poder clerical. O próximo documento estudado foi o código de classificação francês.

O código de classificação francês surge como documento emitido pelo governo revolucionário, em 1791. Considerado o primeiro código nacional de descrição bibliográfica, cujo objetivo era instruir a coleta de informação sobre os livros espalhados em bibliotecas particulares e em posse da Igreja, para controle do estoque. A intenção era desenvolver catálogos que pudessem auxiliar na tomada de decisão sobre a venda de parte de livros (geralmente repetidos) para arrecadar dinheiro para o governo. O projeto caminhou junto com o estabelecimento das bibliotecas públicas pelo Estado.

A autoria do código é atribuída a Jean Baptiste Massieu, mas é resultado da colaboração de várias pessoas que participavam da comissão destinada ao arrolamento dos livros e outros patrimônios. Os catálogos deveriam ser montados para tornarem-se uma fonte de "conhecimento exato de todos os livros, tanto impressos como manuscritos, existentes nas bibliotecas de cada departamento que fazem parte da propriedade nacional.” (MASSIEU, 1791, p. $3)$.

O código é um documento curto e explica detalhadamente o processo que consiste em padronizar as cartas em um mesmo tamanho, colocá-las nos livros, numerá-las na sequência e transcrever nelas as informações contidas na folha de rosto dos livros. Em seguida, ordenam-se as fichas em ordem alfabética e, com uma agulha, furam-se os cartões para mantê-los seguramente juntos 
(MASSIEU, 1791). A folha de rosto é pela primeira vez padronizada como a principal fonte de informação para os registros bibliográficos. (MELOT, 2012).

Há instrução para transcrever as informações da folha de rosto para o cartão e sublinhar a autoria e, em caso de não identificar o autor, o grifo deve ser atribuído ao título. O código recomenda, ainda, incluir no cartão informações sobre o local de impressão, responsabilidade de publicação, o volume da edição, o tamanho da obra, informações sobre ilustração, o material de que é feito o livro se há páginas ausentes, descrição da encadernação e o ano de publicação. (MASSIEU, 1791).

Diferentemente da obra de Naudé, que retrata o livro como um instrumento humanista que corrobora a razão e a erudição, no código francês encontramos uma representação mais técnica. O livro é designado de modo frio, visto como objeto. Não são destacadas as dimensões sociais, tampouco sua capacidade afetiva. Se Naudé destacou livros de autores clássicos e humanistas em contraste com obras medievais, no código não houve distinção sobre valores ou relevância de obras especificas. A diferenciação se dá mais sobre a condição física do livro, isto é, se ele está danificado ou se sua encadernação é comercialmente valiosa.

A palavra "livro" é empregada junto com outros termos, como "títulos dos livros" (MASSIEU, 1791, p. 3), "formato do livro" (MASSIEU, 1791, p. 4) e "se o livro estiver incompleto" (MASSIEU, 1791, p. 7). Nota-se que o livro é simbolicamente descrito como um objeto do qual derivam propriedades. $\mathrm{O}$ enfoque é técnico e objetiva a operacionalização do livro para construção de catálogo em fichas. No século XVII, o discurso sobre o livro começa a tornar-se pragmático, além de ser entendido como um recurso do Estado.

Uma noção iluminista do livro se consolida. O livro é visto como recurso do Estado, para servir ao Estado e, assim, à revolução e ao povo. Juntamente a intenção de vender parte das obras, outras motivações animavam a construção dos catálogos, a construção de bibliotecas públicas e espaços públicos de educação. O livro é considerado como elemento para aprimoramento da razão, mais que de erudição, cujo intuito é afinar o cidadão, que deve ter acesso público às obras preservadas em bibliotecas mantidas pelo 
estado. Faróis do conhecimento, os livros são elementos fundamentais aos ideais iluministas.

A obra icônica do século XIX selecionada foi publicada em 1841, Catalogue of Printed Books in the British Museum, por Antonio Panizzi. O bibliotecário italiano foi diretor da biblioteca do Museu Britânico, então Biblioteca Nacional do Reino Unido. Embora as regras tenham sido formuladas sob as necessidades da biblioteca do museu, essa publicação foi um marco no campo da descrição bibliográfica e tornou-se base dos códigos de catalogação desenvolvidos posteriormente, como o International Standard Bibliographic Description e o Dublin Core.

Panizzi era um ativista político em prol da unificação italiana, tendo sido condenado por publicar a obra Dei Processi e delle Sentenze contra gli imputati di Lesa-Maestà e di aderenza alle Sette proscritte negli Stati di Modena, em 1823. Chegou à Inglaterra fugido e, mesmo assim, participou da unidade italiana, movimento conhecido como Risorgimento, buscando apoiadores ingleses à causa. Tornou-se professor de literatura italiana na University College London e bibliotecário no Museu Britânico. Sua gestão à frente da biblioteca foi de destaque, pois tornou a biblioteca a maior do mundo até então e colaborou fortemente para surgimento do direito do autor no Reino Unido.

Na regra número I, Panizzi afirma que o catálogo deve estabelecer o ponto de acesso pelo nome do autor e ordená-lo alfabeticamente. Refere-se à autoria também na regra XIV, ao indicar que se deve buscar pelo nome do autor e deve-se utilizar colchetes para informações incertas ou adicionais. Na regra XVIII, refere-se ao 'título do livro' e na XX à página, ao cabeçalho da página e ao colofão do livro. O local da publicação e o impressor do livro são citados como informações a serem expressas na catalogação na regra XXVII. A autoria deve dar preferência ao pseudônimo, seguida do nome real do autor entre parênteses, segundo a regra XLI. Define os procedimentos para estabelecer as referências cruzadas a partir da regra LW, cruzando autores e obras, além de conferir destaque aos editores e biógrafos na regra LXI.

O livro aparece ainda mais objetificado, elemento sem dimensão aurática. O foco do catálogo é apresentar a Bibliografia do Museu Britânico, e as 
regras são uma descrição dos métodos adotados. É preservada a perspectiva do livro iluminista como elemento técnico a ser utilizado pelo povo, para um amplo acesso. Esse era o principal objetivo de Panizzi com a confecção do catálogo:

Eu quero que um estudante pobre tenha os mesmos meios de satisfazer sua curiosidade, seguir suas ocupações racionais, consultar as mesmas autoridades, imaginar a mais intricada investigação, como o homem mais rico do reino, até onde os livros vão e eu afirmo que o governo está obrigado a dar-lhe a assistência mais liberal e ilimitada a esse respeito. (PANIZZI apud SCHREIBER, 1979, p. 113).

A contragosto de grande parte dos curadores do museu, Panizzi defendia um catálogo por autor e não um catálogo classificado. $O$ enfoque sobre a autoridade de Panizzi talvez seja resultante de suas crenças no poder do indivíduo de modificar a realidade, na concepção de um ator capaz de criar uma outra realidade. A literatura foi o espaço onde a ideia de nação se consolidou, e o professor de literatura italiana Panizzi compreendia, sonhava com uma única nação para os italianos, vinculados pelo comum já trabalhado pela literatura, presente nos livros. Eram essas as ideias que deveriam proporcionar aos homens o ânimo político. Esse sujeito, que poderia unificar a Itália, também poderia imprimir esse catálogo de autoridade bibliográfica da coleção nacional britânica, tarefa considerada por muitos como inviável devido ao esforço e aos custos envolvidos. (SCHREIBER, 1979).

É importante ratificar o posicionamento de Panizzi sobre o controle de autoridade como ponto de acesso e relacionar isso com seu ativismo político, pois notamos que essa ideia não é compartilhada com os bibliotecários em outros locais. Com base nas regras de Panizzi, Jewett, no contexto estadunidense, propunha o enfoque do catálogo sobre o assunto dos livros.

O bibliotecário italiano apresenta um conjunto de regras refinadas, nas quais o livro apresenta-se em dimensão técnica. A normatização do processo de catalogação das obras é rigorosa, tal como a exigiriam os métodos científicos que começavam a ser definidos no âmbito das Ciências Sociais. Definimos essa noção de livro como romântico.

O livro humanista em Naudé, o livro iluminista de Massieu e o livro romântico de Panizzi são concepções que nos auxiliam na compreensão dos 
dados analisados. Destacamos que mesmo a dimensão técnica do livro é condicionada pelo agenciamento, em que a Biblioteconomia encorpa o espírito positivista para poder ser chamada de Library Science.

O crescimento no número de publicações exigiu dos bibliotecários, bibliógrafos e profissionais afins um grande esforço para a construção de listas e catálogos de livros, a fim de torná-los localizáveis. Essas listas e catálogos eram, e ainda hoje são feitos por processos de extração de propriedade dos livros e condensados em um outro suporte, como um fichário, um livro, em fichas ou em bancos de dados.

\section{0 livro retratado na literatura analisada}

Buscamos bibliografias com passagens que sinalizassem as transformações do livro. A seguir, apresentamos esses resultados para, então, confrontá-los com as perspectivas sobre o livro: o livro humanista, o livro iluminista e o livro romântico. Com isso, poderemos estabelecer conexões entre a transformação do universo livresco e as formas que o campo da Bibliografia e Biblioteconomia desenvolveram para ordenar as informações sobre os livros.

Esta pesquisa é de natureza teórico-exploratória, tendo na empiria um complemento à reflexão conceitual que fundamenta a discussão. Nesse sentido, buscamos livros no catálogo da Biblioteca Central da Universidade do Estado de Santa Catarina (BC/UDESC) que abordassem o tema. No intuito de constituir um corpus que possibilitasse uma análise qualitativa aprofundada, restringimos a busca à livros em língua portuguesa e que de fato destacassem a história do livro nos séculos XVII, XVIII e XIX. Baseados nesses critérios, chegamos a 19 obras, das quais foram analisados os seguintes itens: resumo, sumário, índice e capítulos de cada uma. O corpus foi definido a partir de extrações de trechos textuais que explicitavam uma estabilização do formato livresco ao longo dos períodos históricos pré-definidos.

Realizado o recorte, chegamos a cinco livros que demonstraram maior nível de aderência ao tema e estudo proposto, formando o corpus de análise desta pesquisa conforme quadro abaixo. 
Quadro 1 - Corpus de análise da pesquisa - Livros analisados

\begin{tabular}{|llcc|}
\hline \multicolumn{1}{|c}{ Autoria } & \multicolumn{1}{c}{ Título } & Ano & $\begin{array}{c}\text { Quantidade } \\
\text { de citações }\end{array}$ \\
\hline Robert Escarpit & A revolução do livro & 1976 & 12 \\
Hipólito Escolar & História do livro em cinco mil palavras & 1977 & 12 \\
Jose Barboza Mello & Síntese histórica do livro & 1979 & 07 \\
Steven Roger Fischer & História da leitura & 2006 & 16 \\
Robert Darnton & A questão dos livros & 2010 & 32 \\
\hline Total & & & $\mathbf{7 9}$ \\
\hline
\end{tabular}

Fonte: Dados da pesquisa (2019).

Foram extraídas 79 citações nesses cinco livros, a partir de sete categorias de análise: 'imprensa', 'tiragem', ‘comércio', 'poder', 'formato', 'leitura' e 'percepções'.

Todas as categorias foram analisadas cronologicamente, sendo para isso utilizados cinco momentos distintos: 'século XVII', 'século XVIII', 'século XIX', assim como 'séculos anteriores' - criados para alguns textos que abordavam conteúdo relativo aos séculos XVII, XVIII, XIX o período da Idade Média ou períodos anteriores e, por fim, o período 'Atualidade', que agrupou questões posteriores ao século XIX até os dias atuais.

No entanto, é importante destacar que o foco neste estudo foram, sobretudo, os séculos XVII, XVIII e XIX.

A análise de cada obra foi feita considerando as seguintes definições para as categorias elencadas anteriormente: na categoria 'imprensa', são encontrados textos que destacam a revolução causada pela prensa móvel de Gutenberg, seu impacto social e cultural; com relação à 'tiragem', destaca-se o aumento das tiragens que impulsionaram a circulação de livros na Europa; em 'comércio', destaca-se o barateamento dos preços, motivado pela adoção do papel, aumento na produção, padronização de medidas do livro e de tipografia; a categoria 'poder' revela que o livro foi um objeto que conferia status ao seu possuidor, um signo que indicava o "valor social" do colecionador; na categoria 'formato', relata-se que o livro foi diminuindo de tamanho, o que barateava custos de papel e encadernação. Foram adotados os formatos in-octavo e duodécimo, padrões que propiciaram livros mais fáceis de transportar e espalhar ideias; com relação à 'leitura', aponta-se que a leitura foi democratizada pelo barateamento do material e pela alfabetização das pessoas; outro aspecto de destaque é que durante os séculos analisados, a tradição oral, da leitura pública, 
vai deixando de existir em espaços públicos, fazendo com que o processo de leitura se torne silencioso, individual e solitário; por fim, em 'percepção', compreende-se que a difusão e seu barateamento fizeram com que o livro perdesse parte de sua capacidade de ser um artefato de 'valor social'.

A partir desse levantamento, pretendemos estabelecer as relações dos elementos identificados com os eventos marcantes que animaram a consolidação da Modernidade e identificar efeitos que a estrutura livresca coproduziu na trajetória sócio-histórica desse período.

Com relação à categoria 'comércio', o período em questão destaca o desenvolvimento de uma dinâmica nova. Como resultado da invenção de Gutenberg, o comércio de livros e pergaminhos é alterado e novas rotas são criadas. Grandes cidades tornam-se espaços de publicação e de difusão dos mais variados códices. A proliferação de livros retira o caráter de exclusividade presente até então aos detentores de manuscritos. Isso diminui o valor do livro enquanto 'relíquia' e amplia seu reconhecimento a partir das ideias portadas, o que impulsiona o discurso do acesso público aos livros, como Naudé defendia.

Darnton (2010) destaca a formação de "círculos concêntricos", orientadores da dinâmica do livro: nos grandes centros formavam-se monopólios de editores, consolidavam-se mercadores especializados em livros velhos e em encadernação, que fomentavam clubes de leitura; o comércio de livros chegava à áreas mais remotas e aumentava o número de vendedores que se arriscavam negociando livros proibidos. Surge a fiscalização voltada à busca de obras condenadas por seu conteúdo ou autoria e leis para o combate da pirataria bibliográfica, contudo tais ações não inibiam a circulação de livros censurados ou pirateados.

Com relação ao formato, o século XVII é um período de transformação. Os livros em diversos tamanhos tornam-se comuns. As dimensões do padrão infólio, predominante em período anterior, passa a dividir espaço com o in-quarto e o in-octavo. Elementos como a qualidade do papel e a encadernação são valorizados no comércio, são considerados na experiência do leitor. Nessa época, ainda eram comuns leituras públicas, mas amplia-se a leitura silenciosa. Em ambas as leituras, cresce o interesse por obras não clericais. 
A veneração sobre o livro diminui - dobrar o canto da folha para marcar um ponto da leitura torna-se comum entre os estudiosos -, dado o número de obras que são disponibilizadas pelas editoras e livreiros, contudo, a categoria do livro enquanto objeto de arte surge sob interesse de um público restrito.

O livro é um ser socialmente precioso. O estabelecimento de dinâmicas comerciais, as rotas pelos quais escoam as obras proibidas, as novas relações com a leitura silenciosa, a preocupação com o conteúdo dos livros, a popularização de formatos menores e o aumento das coleções e bibliotecas de acesso público: todos esses eventos compõem a ideia de livro que denominamos por humanista. É inaugurado um novo momento, em que o livro passa a ser um objeto fundamental à sociedade e participará de modo ativo na sua organização. A razão torna-se o instrumento para o desenvolvimento da ciência, da política, da economia, e os meios para o desenvolvimento e promoção da razão são os livros. Os espaços de cultura e educação são diversificados, surgem laboratórios, jardins botânicos, gabinetes e bibliotecas, agenciando uma cultura intelectual diversa daquela que fora restrita aos monastérios. No próximo século, o livro consolida-se como fundamento da sociedade e torna-se um objeto de preocupação formal do Estado.

Foram levantados 12 trechos para o período do século XVIII, envolvendo as categorias: tiragem, comércio, poder, formato, leitura e percepção.

Nesse período, a demanda aumentou consideravelmente, ampliando o número de livreiros. O período é marcado pelo predomínio da palavra impressa, que até então dividia grande espaço com o manuscrito. Dessa maneira, o livro mecanicamente consolida-se como principal meio de preservar e transmitir informações registradas.

A busca do poder estatal no combate à pirataria bibliográfica continuava, mas não inibia a circulação de livros "ilegais". Nesse período, ampliou-se o número de intelectuais no debate público, sobretudo pela difusão e especialização dos periódicos científicos. O debate sobre as ideias registradas nos livros era incentivado, o que impulsionava a publicação de novas ideias. Do debate sobre a classificação dos seres com Carlos Lineu e o conde de Buffon, 
sobre os gases com Lavoisier e Boyle, entre outros debates fortalecidos, como os de David Hume e Kant, Voltaire e Rousseau, Diderot e d'Alembert.

No início do século XVI, a iniciativa de Aldo Manuzio de baratear o livro diminuindo suas dimensões se espalhou pela Europa, e uma maior parcela da população teve recurso para compra desse objeto. Pelo seu preço, contudo, o livro ainda estava muito restrito aos círculos intelectuais o que se modificaria no século XIX. Houve um incremento na produção e com isso, o filtro dos editores tornou-se uma questão que interfere no acesso.

Nesse século, a encadernação entra em crise e os profissionais buscam capas mais econômicas para ampliar as vendas. Contrariamente a isso, surge a percepção do livro enquanto objeto de arte, tendo início nas obras do tipógrafo e pintor londrino William Blake.

No período em questão, é inventada a máquina a vapor e são estabelecidas repúblicas liberais. O livro torna-se um objeto que guarda as normas que devem regular a sociedade, seja do ponto de vista legal, seja da produção. Controlar os livros torna-se uma questão do Estado, que deve promover o acesso às obras e incentivar as ciências.

Com relação ao século XIX, um total de 13 trechos foram recuperados e organizados pelas categorias: imprensa, tiragem, comércio, poder, leitura e percepção.

Inicia-se o período chamado Era das Grandes Tiragens (ESCARPIT, 1976), graças ao barateamento do papel e ao avanço técnico na impressão, que adquiria "prensa metálica, prensa de rolos e a pedal, prensa mecânica a vapor" (ESCARPIT, 1976, p. 24). Com isso, aumenta-se o consumo do texto científico, da literatura e da imprensa jornalística. Ocorre finalmente a massificação do mercado de livros, o que impulsiona a publicação de guias e manuais movida pelo interesse popular.

Os livros tornam-se 'objetos comuns' e algo próximo das pessoas que não estão vinculadas diretamente às instituições de pesquisa. Com isso, a sacralidade e autoridade do livro outrora reconhecidas apenas por seu formato são postas em dúvida. Massificam-se a literatura, os romances, contos e poemas. 
A difusão da literatura corrobora a padronização das línguas nacionais e influência no estabelecimento de algo comum entre pessoas que compartilham a geografia, de forma a intensificar o nacionalismo que marcou o século. O livro passa a ser considerado por muitos um "verdadeiro santuário dos mais elevados sentimentos humanos, a ser aberto, experimentado e apreciado por todas as pessoas de modo igualitário" (FISCHER, 2006, p. 231). Um objeto que permite acessar os sentimentos e a subjetividade, além de ser um instrumento de democracia, não apenas por sua acessibilidade, mas também por ser um instrumento da educação para a conquista da liberdade intelectual e social. A biblioteca torna-se um espaço institucional fundamental. Nesse contexto, valoriza-se o conteúdo do livro, preocupa-se com o texto e não tanto com a mídia, como afirmam Darnton (2010) e Fischer (2006).

O interesse popular pelo livro aumenta. Demandas sociais por ele se conformam nas instituições de educação e cultura. A variedade de forma e conteúdo dos códices amplia-se e, com isso, a tarefa de fazer o leitor-usuário e o livro se encontrarem adquire maior relevância social. Nesse período que se formaliza a profissão de bibliotecário, evidencia-se quão importante seria a informação em breve. Formalizam-se também as Ciências Sociais e Humanas, para as quais os livros constituem-se em base para seus constructos.

\section{5 À guisa de concluir: releituras do livro}

Do livro à informação, motivado pelo desenvolvimento de novos suportes, a Biblioteconomia buscou modernizar-se adotando o conceito de informação como objeto, compreendida na cadeia dado-informação-conhecimento. Há certo mecanicismo nessa perspectiva, em que cada elemento agrega valor semântico e avança de nível, de dado para informação, de informação para conhecimento.

Em vez do mecanicismo, optamos por uma visão alternativa, em que não existe um objeto apartado do mundo, sem agência. A informação não é o resultado de um processamento de dados, apenas. É efeito de conexões que atravessam ao longo da história diferentes esferas e tensões. Dessa forma, a própria noção de "livro" pode ser retomada sem prejuízo aos novos meios que desafiam os saberes e a arte da bibliografia. Não mais o "livro clássico", 
composto por uma interioridade definida por um autor que delimita um assunto sob signos. Um livro é antes definido por suas relações em potência com o mundo social, no sentido que propõe Deleuze e Guattari (2011) com o conceito de livro-rizoma.

Retomamos o livro enquanto fenômeno para compreender em que medida esse se estabelece no imaginário social. O livro se dissemina atrelado ao dispositivo da Igreja medieval, modifica seu status a partir da prensa de Gutenberg, ocupando espaço de destaque na Era das Luzes. Difunde-se com o barateamento da produção no século XIX, tornam-se elemento importante na constituição do sentimento ufanista via a diversificação dos gêneros literários. Nessa enseja, as técnicas e tecnologias do livro são transformadas, assim como as políticas de acesso aos livros.

As práticas bibliográficas acompanharam tais transformações. Da mesma forma que na Modernidade o Estado e o cidadão se individuaram, foi promovida uma nova compreensão do livro. Do livro humanista, que ainda preservava um olhar encantado sobre o objeto bibliográfico, ao livro romântico, que o torna suporte retificado e base de um discurso nacionalista, a perspectiva bibliográfica caminhou numa direção de cientificização. Talvez seja nesse percurso que nasceu o desejo que posteriormente projetou uma nova ciência, que lidaria de maneira mais dinâmica com as informações, como defendia Bush (1945) em As we may think.

Grifamos, por fim, que a validade da pesquisa tem de ser considerada em relação ao universo delimitado e às suas ações metodológicas. Isso significa dizer que não é possível, a partir dos resultados alcançados, generalizar as inferências e conclusões. Os recortes operacionalizados e as opções metodológicas para sua observação impõem restrições, mas foram fundamentais à operacionalização da pesquisa.

\section{Referências}

BUSH, V. As we may think. The atlantic monthly, v. 176, n. 1, p. 101-108, 1945.

DARNTON, R. A questão dos livros: passado, presente e futuro. São Paulo: Companhia das Letras, 2010. 231 p. 
DELEUZE, G.; GUATTARI, F. Mil platôs: capitalismo e esquizofrenia 2. São Paulo: Editora 34, 2011. v.1.

ESCARPIT, R. A revolução do livro. Rio de Janeiro: Fundação Getúlio Vargas, Instituto de Documentação; INL, 1976. 156 p.

FISCHER, S. R. História da leitura. São Paulo: UNESP, 2006. 337 p.

FEBVRE, L.; MARTIN, H-J. O aparecimento do livro. São Paulo: Edusp, 2017.

MASSIEU, J-B. Instruction pour procéder à la confection du catalogue de chacune des bibliothèques sur lesquelles les directoires ont dû ou doivent incessamment apposer les scellés. 1791. Disponível em:

https://gallica.bnf.fr/ark:/12148/bpt6k64658219/f5.image. Acesso em: 23 abr. 2019.

MCKENZIE, D. F. Bibliografia e a Sociologia dos Textos. São Paulo: Edusp, 2018.

MELOT, M. Livro. São Paulo: Ateliê Editorial, 2012.

NAUDÉ, G. Conselhos para formar uma biblioteca. Brasília: Briquet de Lemos, 2016.

OTLET, P. Tratado de documentação: o livro sobre o livro teoria e prática. Brasília: Briquet de Lemos/Livros, 2018.

PANIZZI, A. 91 Rules for Compilation of the Catalogue. In: Catalogue of Printed Books in the British Museum, v. 1. Londres: Department of Printed Books at the British Museum, 1841. p. iii - iv.

RASTELI, A. A evolução da palavra escrita e o acesso às novas formas de construção de sentido. Páginas a\&b: arquivos e bibliotecas, p. 102-116, 2015. Disponível em:

http://ojs.letras.up.pt/index.php/paginasaeb/article/view/1000/902. Acesso em: 23 abr. 2019.

SCHREIBER, M. R. Antonio Panizzi (1797-1879). Revista da Escola de Biblioteconomia da UFMG, v. 8, n. 2, 1979. Disponível em: www.brapci.inf.br/index.php/article/download/16110. Acesso em: 23 abr. 2019. 


\title{
The Book Structure as a Matrix of Arrangement of Knowledge
}

\begin{abstract}
We intend to discuss the notion of books and what this artifact implied in the construction of Modernity, in the sense of the understanding of knowledge and the circulation of information. The research is bibliographical and exploratory and focused on the history of the book between the end of the Middle Ages and the present. With a bibliographical survey, we established relationships of the elements by identifying significant events that boosted the consolidation of Modernity, in order to identify effects which the structure of books coproduced in the socio-historical trajectory in this period. As a theoretical foundation, we started off with the conception that the book is not only an object, but an element that articulates with the world. In this sense, the book is neither mere informational support nor a mere compound of content and form. The simplifying chain data-information-knowledge is questioned, because it is an instrumental division, conditioned by a mechanistic view of reason. This way, the concept of books argues that a book, before having a subject (author) and an object (topic), contains informative matters of different speeds, and is defined primarily by its materiality and exteriority. This understanding displaces any documentary or informational gesture, because categories such as author, subject or format lose relevance in relation to the correlations that a book is composed of. Therefore the need to think about such correlations, in order to broaden the traditional approaches that predominate in the areas that share interest in the book. It is necessary to think of links between the book and the world.
\end{abstract}

Keywords: History of the book. Non-object book. Bibliography. Organization of knowledge.

Recebido: 30/04/2019

Aceito: 02/07/2019

${ }^{1}$ MALLARMÉ, Stéphane. Um lance de dados. Cotia: Ateliê, 2013. 104 p. 